\section{Need for Greater Scrutiny of Days Supply Values in DACON Calculations}

To the Editor:

Daily average consumption (DACON) is a technique used by pharmaceutical companies and managed care organizations to determine drug product cost per day of therapy. This method enables cost comparisons of agents with similar therapeutic indications. It may be reliable for solid dosage forms but can lead to aberrant results when applied to topical pharmaceuticals. Formulary decision makers could draw misleading conclusions about the daily cost of therapy.

DACON is routinely calculated using claims data by dividing the total days supply of a product by the total units (tablets, capsules, milliliters, etc.) dispensed. To better illustrate the pitfalls of DACON calculations, we'll refer to an actual case involving a large eastern Medicaid program and a decision it was trying to reach concerning topical ophthalmic agents. The Medicaid plan in question decided to create a preferred drug list (i.e., a formulary) to better manage its costs. It looked at the aggregate data from its pharmacy benefit manager (PBM) for a 2 -month period. Table 1 shows the initial DACON calculations that were prepared for presentation to the state's Medicaid pharmacy director.

As can be noted in this table, it indicates that 4.55 milliliters of Lumigan are being used daily as are $6.5 \mathrm{mls}$ of Travatan and 7.5 mls of Xanatan. We know these utilization results lie beyond common sense, leading us to presume that using the DACON calculations that one would use for solid dosage forms simply do not work in this case.

Pharmacists and pharmacy technicians tend to use routine values for the days supply field to avoid rejection of prescription claim transactions. For example, the standard days supply for topical products is 15 days; for inhalation, otic, or ocular preps, 15,20 , or 30 days. The objective in most community pharmacies is to fill the prescription as efficiently as possible, estimating the days supply using shortcuts or a rule of thumb for the days supply field. Claims processing systems used by PBMs will routinely reject a refill claim if the refill date is too soon (based on the date of the prior fill); i.e., if the refill date is not equal to or greater than a certain percentage, such as $80 \%$, of the estimated days supply entered on the prior fill, the claim will be rejected. What is considered "efficient" pharmacy practice by the chain pharmacies also renders incorrect the DACON calculations that are derived from the days supply values.

The industry standard benefit design among PBMs is to not adjudicate a claim for a supply greater than 30 days in a community pharmacy. While some exceptions may exist in some drug benefit designs, i.e., oral contraceptives or insulin, the 30-day paradigm is still utilized. Since the average chain pharmacy deals with hundreds of different payer plans, it's easy to see why these "rules" exist. Since PBM claim systems sometimes are programmed to not accept a days supply greater than 30 , this is the maximum number entered even though the pharma-

\begin{tabular}{lcccc}
\hline TABLE & 1 & DACON & Calculations & \\
\hline Drug & Total mLs & Total Rx & Total Days & Dacon \\
Name & Dispensed & Count & Supply & mLs/Day \\
\hline Lumigan & 6,819 & 1,556 & 31,015 & 4.55 \\
Travatan & 3,205 & 1,055 & 20,836 & 6.50 \\
Xalatan & 15,565 & 5,098 & 116,902 & 7.51 \\
\hline mls = milliliters. & & & \\
\hline
\end{tabular}

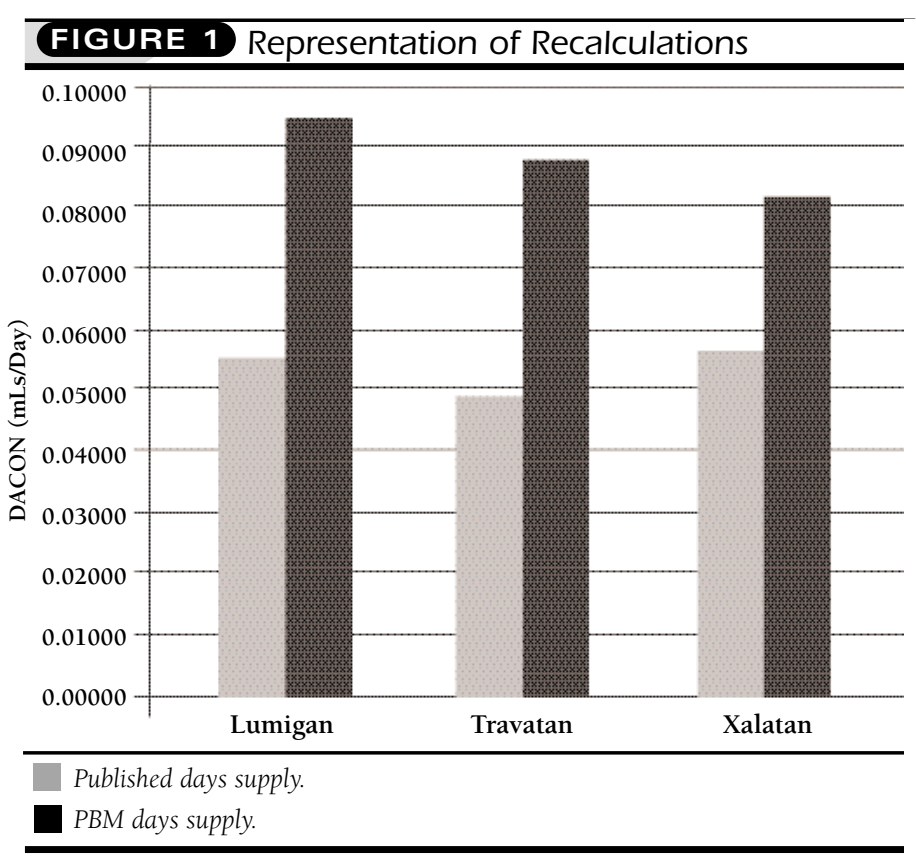

cy personnel know that the prescription will often exceed that number of days.

In the case where a product is available in different volume bottles, each with a different market share, the DACON calculations become even more confusing. Table 2 shows 2 sets of calculations based on the PBM data from Table 1 where the DACONs have been recalculated using different, yet realworld, criteria. Calculation 1 shows the DACONs for the prostaglandins and prostamide agents using the total prescriptions as reported by the PBM and the days supply per bottle as reported in the literature. Calculation 2 shows the DACONs based on the days supplies that were most likely entered by the community pharmacies that are generally permitted by PBM systems. Figure 1 gives a visual representation comparing the 2 calculations in Table 2.

A dataset with only 2 months of data may also lead to anomalies in the calculations. For example, since 60 days is less than the estimated days supply of larger size or multiple-container prescriptions, a refill cycle is not captured. This "clipping" of the data would result in falsely shortening the days supply when actual refill dates (in lieu of the entered days supply) are 
Calculation 1

Recalculation Based on Actual Rxs and Published Days Supply*

\begin{tabular}{|c|c|c|c|c|}
\hline Lumigan & \multicolumn{2}{|c|}{ 1,556 Rxs } & \multicolumn{2}{|c|}{6,819 Total Units } \\
\hline Size (mL) & 2.5 & 5 & 7.5 & Total \\
\hline National SKU mix & $55.20 \%$ & $43.10 \%$ & $1.70 \%$ & $100 \%$ \\
\hline Rxs & 859 & 671 & 26 & 1,556 \\
\hline Days/Rx & 54 & 95 & 129 & \\
\hline Total days & 46,381 & 63,710 & 3,412 & 113,504 \\
\hline & & $\begin{array}{l}\text { Days Sup } \\
\text { DACON }\end{array}$ & $\mathrm{Rx}$ & $\begin{array}{r}72.95 \\
0.06008\end{array}$ \\
\hline
\end{tabular}

\begin{tabular}{|c|c|c|c|}
\hline Travatan & \multicolumn{2}{|c|}{ 1,055 Rxs } & 3,205 Total Units \\
\hline Size $(\mathrm{mL})$ & $2.5 \mathrm{~mL}$ & $2 \mathrm{pak}$ & \begin{tabular}{l|l} 
& Total \\
\end{tabular} \\
\hline National SKU mix & $90.20 \%$ & $9.80 \%$ & $100 \%$ \\
\hline Rxs & 952 & 103 & 1,055 \\
\hline Days/Rx & 51 & 102 & \\
\hline Total days & 48,532 & 10,546 & 59,078 \\
\hline & & $\begin{array}{l}\text { Days Su } \\
\text { DACON }\end{array}$ & $\begin{array}{r}56.00 \\
0.05425\end{array}$ \\
\hline
\end{tabular}

Xalatan
\begin{tabular}{|l|c|c|c|c|}
\hline Size (mL) & 5,098 & Rxs & 15,565 & Total Units \\
\hline National SKU mix & $91.20 \%$ & $8.80 \%$ & & Total \\
\hline Rxs & 4649 & 449 & & $500 \%$ \\
\hline Days/Rx & 42 & 126 & & 5,098 \\
\hline Total days & 195,274 & 56,527 & & 251,800 \\
\hline \multicolumn{5}{|c|}{ Days Supply Rx } \\
DACON & 49.39 \\
\end{tabular}

\section{Calculation 2}

Recalculation Based on Reported Days Supply and Max $\dagger$ Entered Days Supply

Lumigan
\begin{tabular}{|l|c|c|c|c|}
\hline Size $(\mathrm{mL})$ & 2.5 & 5 & 7.5 & Total \\
\hline National SKU mix & $55.20 \%$ & $43.10 \%$ & $1.70 \%$ & $100 \%$ \\
\hline Rxs & 859 & 671 & 26 & 1,556 \\
\hline Days/Rx & 30 & 60 & 90 & \\
\hline Total days & 25,767 & 40,238 & 2,381 & 63,386 \\
\hline \multicolumn{5}{|c}{ Days Supply Rx } \\
DACON & 43.95 \\
\end{tabular}

\begin{tabular}{|c|c|c|c|}
\hline \multicolumn{4}{|c|}{ 20,836 Total Days Supply } \\
\hline Size $(\mathrm{mL})$ & $2.5 \mathrm{~mL}$ & $2 \mathrm{pak}$ & Total \\
\hline National SKU mix & $90.20 \%$ & $9.80 \%$ & $100 \%$ \\
\hline Rxs & 952 & 103 & 1,055 \\
\hline Days/Rx & 30 & 60 & \\
\hline Total days & 28,548 & 6,203 & 34,751 \\
\hline & & $\begin{array}{l}\text { Days S } \\
\text { DACO }\end{array}$ & $\begin{array}{r}32.9 \\
0.0922\end{array}$ \\
\hline
\end{tabular}

Xalatan
\begin{tabular}{|l|c|c|l|c|}
\hline Size (mL) & 116,902 & Total Days Supply \\
\hline National SKU mix & $91.20 \%$ & $8.80 \%$ & & Total \\
\hline Rxs & 4,649 & 449 & & 5,098 \\
\hline Days/Rx & 30 & 90 & & \\
\hline Total days & 139,481 & 40,376 & & 179,857 \\
\hline \multicolumn{5}{|c|}{ Days Supply Rx } \\
DACON & 35.28 \\
\end{tabular}

* Assumed maximum entered days supply: $2.5 \mathrm{~mL}=30$ days, $5.0 \mathrm{~mL}=60$ days, $7.5 \mathrm{~mL}=90$ days, based on generally accepted practice permitted by PBM systems. + Utilized total units ( $m L s)$ as provided in original data set.

used to compute the length of time.

The SKU numbers used in Table 2 show the national SKU mix. These are the total annual sales in the United States and are shown as percentages of each package size of each of the 3 products. (For example, 55.2\% of all Lumigan sales are for the $2.5 \mathrm{ml}$ bottle.) The SKU mix was not used in the calculations in Table 1 , acting as one of the factors that led to erroneous results. We realize that Calculation 1 in Table 2 assumes that the patients waste no medication, i.e., do not miss the eye, lose a drop, etc. This is a best-case scenario. Calculation 2 shows how the DACONs can be skewed by using the days supply that most PBMs use as defaults. This represents the worst-case scenario.

In either case, the estimations of the DACONs for these 3 products are still more accurate than the calculations using empirical PBM data as shown is Table 1. We suggest using a weighted average of the 2 calculations from Table 2 , yielding a more accurate, cost-effective representation of the data. This technique would be of greater practical benefit to managed care organizations and Medicaid programs. Such calculations need to be based upon considerations of different volumes of commercially available sizes, their SKU mix, and published data when available.
Charles C. Lewis, BS Pharm, CPh, MBA

Managing Partner, Clinical Coordinator Jasos Group, LLC 801 International Pky, 5th Flr. Lake Mary, FL 32746 tlewis@jasos.com

\section{Richard G. Fiscella, BS Pharm, MPH \\ Clinical Professor \\ University of Illinois at Chicago}

Tim Kosty, BS Pharm, MBA

President

Pharmacy Healthcare Solutions, Inc.

Pittsburgh, PA

\section{DISCLOSURES}

Charles C. Lewis is a consultant and researcher for Allergan. Richard G. Fiscella is a consultant and researcher for Allergan and Pharmacia Upjohn.

\section{REFERENCES}

1. Fiscella RG, Green A, Patuszynski DH, Wilensky J. Medical therapy cost considerations for glaucoma. Am J Ophthalmol. 2003;136:18-25. 
Other DACON Observations

\section{Community Pharmacists Do Not Intentionally Transmit Incorrect Claim Information-But Caution Is Warranted in Days Supply Calculations}

\section{To the Editor:}

Much of the information in the letter by Lewis, Fiscella, and Kosty is accurate. ${ }^{1}$ However, the authors claim that community pharmacists routinely use inaccurate days supply estimations for the "efficient" purpose of working against the inefficient days-supply (refill-too-soon) edits imposed by pharmacy benefit managers (PBMs). While community pharmacists are consistently challenged by inefficient refill-too-soon edits, my experience with community pharmacist and community pharmacy management confirms that pharmacists provide the most accurate days supply estimation based on known information. Pharmacists and pharmacy technicians tend to use routine values for the days supply field because they do not have more specific information.

In addition, I disagree that pharmacy personnel would intentionally misrepresent days supply as 30 when they know that the prescription "will often exceed that number of days." This practice would be considered fraudulent. However, I agree that if pharmacy personnel do not know the accurate days supply, they will often err on the side of "efficient" pharmacy practice and use 30 as an estimation. Their failure to do so would limit patient access to medications and compromise patient care, hardly the intended outcome.

Community pharmacists are not responsible for nor do they have the time to perform complicated calculations to provide exact days supply data on prescription claims. Their primary role is to improve medication use and advance patient care, not assure absolute precision in a calculation somewhat tangential to a payment claim submission. For topical medications, eye drops, and insulin, they often do not have the necessary information to make those calculations.

We all would like to see claims data be as accurate as possible, not just for financial transactions but also for clinical practice and disease management. I agree with the authors that, without accurate information, PBMs receive falsely shortened days supply data. However, I think it is unfair to state that, without additional data, pharmacists intentionally report incorrect days supply. As the authors noted, it is probably best to use other data sources for calculating DACON and recognize the limitations of claims data.

John A. Gans, PharmD Executive Vice President and CEO American Pharmacists Association 2215 Constitution Ave., NW Washington, DC 20037-2985 JGans@APhAnet.org

\section{DISCLOSURES}

The author states that he has no conflict of interest or any potential bias regarding this letter.

\section{REFERENCE}

1. Need for greater scrutiny of days supply values and DACON calculations. J Manag Care Pharm. 2004;10(2):172-73.

\section{To the Editor:}

I think pharmacists do a good job in reporting days supply in prescription claims for tablets and capsules, but it is more challenging to report accurate days supply for other dosage forms such as inhalers, eye drops, and topicals. Pharmacists may use lower estimates of days supply to avoid refill-too-soon rejections, but they use averages because they are just that-averages-based on their experience with the products. From this perspective, who is better prepared to provide reliable estimates of days-supply data on prescription claims than those in community pharmacies who routinely dispense these medications?

Using the medical literature to determine how the drugs "should" be used is only modestly helpful when looking at how the drugs are actually used. I believe most health plans frequently use DACON numbers for tablets and capsules but rarely, if ever, rely on DACON for drugs with other dosage forms. I think everyone who uses financial calculations based upon days supply understands the limitations involved and is not surprised by the potentially skewed DACONs for drugs that are not capsules or tablets.

Eric J. Culley, PharmD DUR Clinical Pharmacy Specialist Highmark Blue Cross Blue Shield

120 Fifth Ave., Suite 1812

Pittsburgh, PA 15222

eric.culley@highmark.com

\section{DISCLOSURES}

The author states that he has no conflict of interest or any potential bias regarding this letter.

\section{To the Editor:}

I commend the authors for bringing the topic to this forum for discussion. ${ }^{1}$ This is an example of the type of comparative cost situation that can derail the best intentioned pharmacy and therapeutics (P \& T) committee review.

I typically do not use DACON based on the days supply field from claims data to calculate a cost per day for products such as ophthalmics or topical dermatologicals. I agree with Lewis, Fiscella, and Kosty that the days supply data can be faulty and that this, in part, may be due to pharmacists being 
under pressure to have claims adjudicate without rejection. However, it is also often difficult to estimate the days supply for such products.

When looking to assess drug costs for purposes of formulary decisions, one can search the literature and contact the manufacturers to determine an average days supply by package size. As the authors mention, in the ophthalmic area, one can usually obtain the number of drops per milliliter, which when combined with average daily dosing, the cost per prescription and the bottle size provides an estimated cost per day. Fiscella's recent contribution to this body of literature is an excellent place to find this information for glaucoma products. ${ }^{2}$

Of course this methodology assumes an ideal situation with no wastage, which is not a realistic way to determine an actual cost per day. However, the actual cost per day may not be completely necessary. When making formulary decisions, relative costs across a drug category may be useful, and an estimated cost per day based on ideal usage can be used to generate a relative cost comparison chart. Unless there is reason to believe that there would be significantly more wastage with one product versus another, this would seem a simpler solution to the problem for formulary decision makers.

The authors' letter does not discuss potential wastage differ- ences between products although discussion of potential differences with select glaucoma products can be found in Fiscella's recent article. Although the authors do an excellent job of explaining why the use of a reported days supply DACON may lead to inaccurate results, they do not discuss why using only a "best-case scenario" DACON should not be pursued. I question why they feel that averaging the two DACONs is a better alternative.

Andrea Hess, BS, PharmD Manager, Drug Information WellPoint Pharmacy Management 6003 Vermont Hill Rd. South Wales, NY 14139 Andrea.Hess@Wellpoint.com

\section{DISCLOSURES}

The author states that she has no conflict of interest or any potential bias regarding this letter.

\section{REFERENCES}

1. Need for greater scrutiny of days supply values and DACON calculations. J Manag Care Pharm. 2004;10(2):172-73.

2. Fiscella RG, Green A, Patuszynski DH, Wilensky J. Medical therapy cost considerations for glaucoma. Am J Ophthalmol. 2003;136:18-25.

\section{Letters to the Editor}

$J M C P$ welcomes letters that serve to clarify subjects published in previous issues of the Journal or regarding subject matter of interest to managed care pharmacists. Letters in JMCP are not peer reviewed but are subjected to editorial review. When a submitted letter refers to an article published in a previous issue of the Journal, the letter is sent to the authors of the subject article to allow their response to be published with the letter.

Each letter should be signed by no more than 3 authors. Submissions must include your title, affiliation, complete mailing address, telephone number, and e-mail address. Potential bias or conflicts of interest must be disclosed. Letters should be submitted in electronic format, preferably using Microsoft Word, and may be sent by e-mail to Fred Curtiss, editor-in- chief, at fcurtiss@amcp.org or to Tamara Faggen, managing editor, at tfaggen@amcp.org. 